\title{
3D QSAR Studies on Some 5-(1H-Indol-5-yl)-1, 3, 4-Thiadiazol-2 Amines as Potential PIM-1 Inhibitors
}

Panche Tulesh Kumar, Ghode Piyush, Jain Sanmati Kumar*

SLT Institute of Pharmaceutical Sciences, Guru Ghasidas Vishwavidyalaya, Bilaspur, Chattisgarh, INDIA.

\begin{abstract}
Objective: Proviral integration site for moloney murine leukemia virus (PIM) kinases are among the contemporary targets for cancer chemotherapy as they play a pivotal role in inhibition of apoptosis and oncogenic signaling. Owing to their structural and functional dissimilarity to other kinases, they can be specifically targeted. The present study is an attempt to establish three dimensional quantitative structure activity relationship (3D OSAR) between some 5-(1H-Indol-5-yl)-1,3,4-thiadiazol-2-amines for their inhibitory activity against PIM by partial least squares regression (PLSR) analysis. Method: PLSR coupled with different variable selection methods such as stepwise (forward-backward) (SW), genetic algorithm (GA) and simulated annealing (SA) was performed to derive QSAR models and these models were validated for statistical significance internally and externally and robustness. Results: Two most significant models were generated through GA with optimum values of validation parameters. Among these model 1 exhibited $\mathrm{q}^{2}$ and pred_ $r^{2}$ values of 0.7523 and 0.8714 and model 2 evinced 0.6577 and 0.7675 respectively. The steric field point in model 1 suggests the need of more bulky group at this position and the positive coefficients of electrostatic field points at positions E_999, E_1162 respectively indicate the need of electronegative groups for favorable biological activity. Model 2 suggests the requirement of a positive hydrophobic group at $\mathrm{H}_{-} 564$ and less electronegative and more electronegative group at E_157 and E_630
\end{abstract}

respectively for more potent biological activity. Conclusion: More bulky and/or hydrophobic $\mathrm{R}$ groups apart from the electrostatic contribution may be favorable for better PIM-1 inhibition of 5-(1 H-indol-5-yl)-1,3,4-thiadiazol-2 amines.

Key words: 1,3,4-Thiadiazole-2-amine, PIM, QSAR, Anticancer, PLSR.

\section{Key Message}

The quantitative structure activity relationship analysis on $5-(1 \mathrm{H}$-indol-5-yl)1,3,4-thiadiazol-2 amines was carried out for PIM-1 inhibitory activity. The present study suggested the requirement of steric bulk and/or hydrophobic group at third position of indole ring for better activity.

Correspondence :

Sanmati K. Jain,

SLT Institute of Pharmaceutical Sciences, Guru Ghasidas Vishwavidyalaya, Bilaspur, Chattisgarh, 495009, INDIA

Phone numbers: $07752-260027$

Facsimile numbers: 07752-260148

Email: sanmatijain72@yahoo.co.in

DOI: 10.5530/jyp.2017.9.32

\section{INTRODUCTION}

Proviral integration site for moloney murine leukemia virus kinases (PIM) constitute a family with high sequence and structural similarity (PIM-1, PIM-2 and PIM-3) belonging to serine/threonine kinases. ${ }^{1}$ They differ from other kinases in that they are constitutively activated and regulated at their post trascriptional and post translational levels. Another contrasting difference of PIMs to other kinases is the presence of proline residue in the hinge region of ATP binding pocket in the former which results in a unique molecular recognition site among the kinase family. They are primarily regulated by growth factor and cytokine signaling downstream of PTK/STAT activation. ${ }^{2}$ The role of PIMs is implicated in tumor growth and activation of oncogenic MYC signaling. Their function in tumor growth is attributed to inhibition of apoptosis by targeting the proapoptotic B-cell lymphoma 2 -associated death promoter (BAD). They activate the MYC signaling by phosphorylating the serine residue on histone $\mathrm{H} 3$ on the nucleosome of $\mathrm{c}$-myc binding site, thus contributing to increased trascriptional activation of c-myc over expression or deregulation of PIM-1 and PIM-2 may result in different hematologic cancers such as diffuse large B-cell lymphoma, folicular lymphoma, hodgkin's lymphoma and mucosa-associated lymphoid tissue (MALT) and solid tumors while PIM-3 leads to adenocarcinomas..$^{3-5}$ Owing to the above, PIMs are perceived to be attractive therapeutic targets due to their role in inhibition of apoptosis and promoting cell proliferation.
Compounds having thiadiazole nucleus are reported to have a number of biological activities like antituberculosis, ${ }^{6-8}$ antiproliferative, ${ }^{9,10}$ antibacterial, ${ }^{11,12}$ anticancer, ${ }^{13-15}$ antifungal, ${ }^{16,17}$ antihyperlipidemic, ${ }^{18}$ and anti-inflammatory. ${ }^{19}$ 5-(1H-indol-5-yl)-1,3,4-thiadiazol-2-amines were also reported as potent PIM inhibitors showing excellent potency against all three PIM isoforms. ${ }^{20}$ Quantitative Structure Activity Relationship (QSAR) is a technique to establish the quantitative relationship between physiochemical or structural properties of congeneric series of compounds and their biological activity using statistical methods. It is a part of ligand based drug design which can be utilized for prediction of activity of hitherto experimentally untested compounds. ${ }^{21-24}$ Thus it may prove to be a time and cost efficient method for new lead discovery. The present study is an attempt to determine QSAR between 5-( $1 \mathrm{H}$-indol5-yl)-1,3,4-thiadiazol-2-amines and their PIM-1 inhibitory activity.

\section{MATERIALS AND METHODS}

Three dimensional (3D) QSAR study was performed by Molecular design suite (VLife MDS) software on HCL computer with Intel Pentium dual core processor and Windows XP operating system. ${ }^{25}$ 


\section{Data set}

Twenty two thiadiazole derivatives reported by Wu et al. for their PIM-1 inhibitory activity were used as the data set for QSAR study (training set $75 \%$, test set $25 \%) .{ }^{1}$ The negative logarithmic scale values of concentration required for inhibition of $50 \%$ of enzyme $\left[\mathrm{pIC}_{50}\right.$ (moles)] were utilized as dependent variable for QSAR analysis (Table 1).

\section{Molecular modeling}

2D Draw application of MDS was used to build the molecules that were converted into 3D structures for further analysis. Merck molecular force field (MMFF) was used to optimize the compounds by energy minimization and geometric optimization by considering distance-dependent dielectric constant of 1.0, convergence criterion or root-mean-square (RMS) gradient at $0.01 \mathrm{kcal} / \mathrm{mole}$ and the iteration limit to 10,000 . The calculation of electrostatic, steric and hydrophobic fields on the lattice points of a grid around the molecules was performed on energy minimized structures. These fields were utilized as descriptors for QSAR generation.

\section{Alignment of compounds}

In order to obtain noteworthy results in 3D-QSAR study molecular alignment is a crucial step. The molecules were aligned by template based alignment. To this end a template was defined such that it represents a common fragment present in all the molecules of the data set (Figure 1).

\section{Generation of training set and test set}

In order for statistical significance a QSAR model has to be validated internally and externally. Leave one out cross validation procedure can be used for internal validation. Results of validation can be obtained in the form of cross validated $R^{2}\left(q^{2}\right)$ (the model is accepted if $\left.q^{2}>0.5\right)$. The data set has to be distributed into training set and test set for the purpose of external validation, where the model is developed with the help of the training set and its validation can be done by test set. In the present work the training and test sets were divided using random selection. The training set comprised of $75 \%$ of compounds and rest $25 \%$ of the compounds belonged to the test set.

\section{Feature selection and model development}

Different feature selection methods are available at the researcher's disposal in order to select descriptors for generation of the model from a large pool. Three variable selection methods were applied in for feature selection in this study: (1) Stepwise wearable selection (SW), (2) Genetic algorithm (GA) and (3) Simulated annealing (SA).

\section{RESULTS AND DISCUSSION}

3D QSAR study was performed on a series of thiadiazole derivatives for determination of structural features responsible for improved PIM inhibition. Random selection method was used for division of training and test sets. Partial least squares regression (PLSR) was applied for generation of a number of models from the deferent combination of training sets and test sets which were interpolative i.e. the compounds with maximum and minimum reported activities were in training set and the compound belonging to test set had values within this window. Unicolumn statistics of two most significant models are presented in Table 2. Some of the generated models were statically significant $\left(\mathrm{q}^{2}>0.5\right.$, predr $^{2}>0.5$ ) (Table 3). Further, the robustness of the models was checked by $\mathrm{Y}$ randomization test. The $\mathrm{Y}$ randomization test implies that the higher value of $\mathrm{Z}$ score at a given confidence interval $\alpha$, the higher the ability of model to predict activity of an unknown compound within that confidence interval.

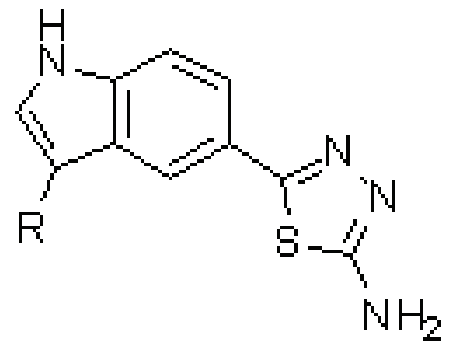

Table 1 : Series of 5-(1H-indol-5-yl)-1, 3, 4-thiadiazol-2-amines with pIC $_{50}$ values

\begin{tabular}{|c|c|c|c|c|}
\hline $\begin{array}{l}\text { S. } \\
\text { No. }\end{array}$ & $\begin{array}{c}\text { Compound } \\
\text { No. }\end{array}$ & $\mathbf{R}$ & $\mathrm{IC}_{50}$ & $\mathrm{pIC}_{50}$ \\
\hline 1 & 3 & quinolin-3-yl & 0.163 & 6.79 \\
\hline 2 & 13 & 2,6-difluoro phenyl & 0.177 & 6.75 \\
\hline 3 & 14 & 6-amino pyridine-2-yl & 0.865 & 6.06 \\
\hline 4 & 15 & 6-(pyrrolidin-1yl)pyridine-2-yl & 0.048 & 7.32 \\
\hline 5 & 16 & 6-morpholino pyridin-2-yl & 0.016 & 7.80 \\
\hline 6 & 17 & 6-isopropylamino pyridin-2-yl & 0.024 & 7.62 \\
\hline 7 & 18 & 6-cyclopentylamino pyridine-2-yl & 0.012 & 7.92 \\
\hline 8 & 19 & 6-cyclohexylamino pyridine-2-yl & 0.109 & 6.96 \\
\hline 9 & 20 & 6-amino pyrazin-2-yl & 0.142 & 6.85 \\
\hline 10 & 21 & 6-pyrolidin-1-yl-pyrazin-2-yl & 0.011 & 7.96 \\
\hline 11 & 22 & 6-morpholinopyrazin-2-yl & 0.005 & 8.30 \\
\hline 12 & 23 & 6-isopropylamino pyrazin-2-yl & 0.002 & 8.70 \\
\hline 13 & 24 & 6-cyclopentylamino pyrazin-2-yl & 0.001 & 9.00 \\
\hline 14 & 25 & 6-cyclohexylamino pyrazine-2-yl & 0.004 & 8.40 \\
\hline 15 & 26 & 6-ethoxy pyridine-2-yl & 0.017 & 7.77 \\
\hline 16 & 27 & 6-isopropoxypyridin-2-yl & 0.007 & 8.15 \\
\hline 17 & 28 & 6-cyclopentyloxy pyridine-2-yl & 0.015 & 7.82 \\
\hline 18 & 29 & 6-cyclohexyloxy pyridine-2-yl & 0.041 & 7.39 \\
\hline 19 & 30 & 6-ethoxyl pyrazin-2-yl & 0.021 & 7.68 \\
\hline 20 & 31 & 6-isopropoxy pyrazin-2-yl & 0.008 & 8.10 \\
\hline 21 & 32 & 6-cyclopentyloxy pyrazin-2-yl & 0.011 & 7.96 \\
\hline 22 & 33 & 5-isopropoxy pyrazin-2-yl & 0.262 & 6.58 \\
\hline
\end{tabular}

Table 2 : Unicolumn statistics for most optimum models

\begin{tabular}{ccccccc}
\hline Model no. & Data set & Average & Max & Min & Std Dev & Sum \\
\hline \multirow{2}{*}{1} & Training & 7.69 & 9.00 & 4.51 & 0.76 & 123.10 \\
& Test & 7.46 & 8.30 & 6.58 & 0.67 & 44.78 \\
\multirow{2}{*}{2} & Training & 7.71 & 9.00 & 6.61 & 0.75 & 123.44 \\
& Test & 7.41 & 8.30 & 6.58 & 0.69 & 44.44 \\
\hline
\end{tabular}

Model 1:

$\mathrm{pIC}_{50}=0.0387757 \mathrm{~S} \_672+10.5355$ E_1162 +12.9437 E_999 +8.49746

No. of training set compounds $=16$, No. of test set compounds $=6$, Degree of freedom $=13, \mathrm{q}^{2}=0.7523, \mathrm{q}^{2} \mathrm{se}=0.3995$, pred_ $\mathrm{r}^{2}=0.8714$, pred_r ${ }^{2}$ se $=0.2762$

The model shows a good internal $(\sim 75 \%)$ and external $(\sim 87 \%)$ validation capability with low standard error values. In this model, descriptor field points at E_999,E_1162 and S_672 are having coefficient values of 12.9437, 10.5355 and 0.0387757 respectively. These points correspond to the elec- 
Table 3 : 3D QSAR analysis results by PLSR method by using random data selection (75\% of training set)

\begin{tabular}{|c|c|c|c|c|c|c|c|c|c|c|}
\hline \multirow[t]{3}{*}{ S. No. } & \multirow[t]{3}{*}{ Test Set Molecules } & \multicolumn{9}{|c|}{ PLSR } \\
\hline & & \multicolumn{3}{|c|}{ SW } & \multicolumn{3}{|c|}{ GA } & \multicolumn{3}{|c|}{ SA } \\
\hline & & $r^{2}$ & $q^{2}$ & pred $r^{2}$ & $r^{2}$ & $q^{2}$ & pred $r^{2}$ & $r^{2}$ & $q^{2}$ & pred $r^{2}$ \\
\hline 1 & $16,17,20,28,31,33$ & 0.76 & 0.62 & 0.91 & 0.83 & 0.66 & 0.15 & 0.70 & 0.52 & 0.68 \\
\hline 2 & $20,23,25,28,32,33$ & 0.84 & 0.75 & 0.47 & 0.80 & 0.70 & 0.63 & 0.74 & 0.45 & -7.93 \\
\hline 3 & $17,20,25,28,32,33$ & 0.84 & 0.73 & -5.89 & 0.77 & 0.65 & 0.67 & 0.67 & 0.42 & 0.67 \\
\hline 4 & $17,19,27,30,32,33$ & 0.91 & 0.85 & 0.21 & 0.89 & 0.81 & 0.20 & 0.78 & 0.62 & 0.05 \\
\hline 5 & $15,17,22,28,30,33$ & 0.84 & 0.77 & -0.02 & 0.75 & 0.57 & -0.24 & 0.64 & 0.46 & 0.34 \\
\hline 6 & $13,19,23,27,32,33$ & 0.89 & 0.81 & 0.60 & 0.88 & 0.76 & 0.29 & 0.80 & 0.70 & 0.08 \\
\hline 7 & $15,16,21,29,31,33$ & 0.87 & 0.81 & -0.41 & 0.80 & 0.65 & 0.77 & 0.73 & 0.58 & 0.38 \\
\hline 8 & $15,20,21,22,26,33$ & 0.87 & 0.75 & 0.53 & 0.85 & 0.18 & -0.28 & 0.80 & 0.67 & 0.07 \\
\hline 9 & $13,15,22,29,31,33$ & 0.82 & 0.74 & 0.34 & 0.85 & 0.75 & 0.87 & 0.66 & 0.43 & 0.48 \\
\hline 10 & $16,18,19,20,22,33$ & 0.89 & 0.81 & -0.69 & 0.80 & 0.65 & 0.76 & 0.61 & 0.37 & 0.18 \\
\hline
\end{tabular}

\section{Table 4 : Statistical parameters for the two most significant models}

\begin{tabular}{|c|c|c|}
\hline Parameters & Model-1 & Model-2 \\
\hline Size of training set & 16 & 16 \\
\hline Size of test set & 6 & 6 \\
\hline Degree of freedom & 13 & 13 \\
\hline $\mathrm{q}^{2}$ & 0.7523 & 0.6577 \\
\hline $\mathrm{q}^{2} \_\mathrm{se}$ & 0.3995 & 0.4689 \\
\hline Pred_r ${ }^{2}$ & 0.8714 & 0.7675 \\
\hline Pred_r ${ }^{2} s e$ & 0.2762 & 0.3735 \\
\hline \multirow[t]{3}{*}{ Descriptor range } & S_672 0.0387757 & E_157 -0.762001 \\
\hline & E_1162 10.5355 & E_630 1.0576 \\
\hline & E_999 12.9437 & H_564 2.44615 \\
\hline
\end{tabular}

trostatic contribution of E_999 and E_1122 and steric contribution of S_672 (Figure 2, Figure 3). The positive coefficient of the electrostatic field indicates that a more electronegative group is important for better activity. The positive value of the steric field point indicates that the substitution of more bulky group at this point will have favorable contribution for biological activity. This inference is supported by higher activities of compounds 22, 23, 24 and 25 with a bulky substituent at pyrazine nucleus as compared to their pyridine counterparts $16,17,18$ and 19 respectively. Other compounds such as 3,13,14 and 20 have less bulky groups and are having less activities.

Model 2:

pIC ${ }_{50}=-0.762001$ E_157 +2.44615 H_564 +1.0576 E_630 +6.20693

No. of training set compounds $=16$, No. of test set compounds $=6$, Degree of freedom $=13, \mathrm{q}^{2}=0.6577, \mathrm{q}^{2}$ se $=0.4689$, pred_ $\mathrm{r}^{2}=0.7675$, pred_r ${ }^{2}$ se $=0.3735$

In this model, the lattice points E_157, H_564, and E_630 show the hydrophobic and electrostatic field at points -0.762001, 2.44615 and

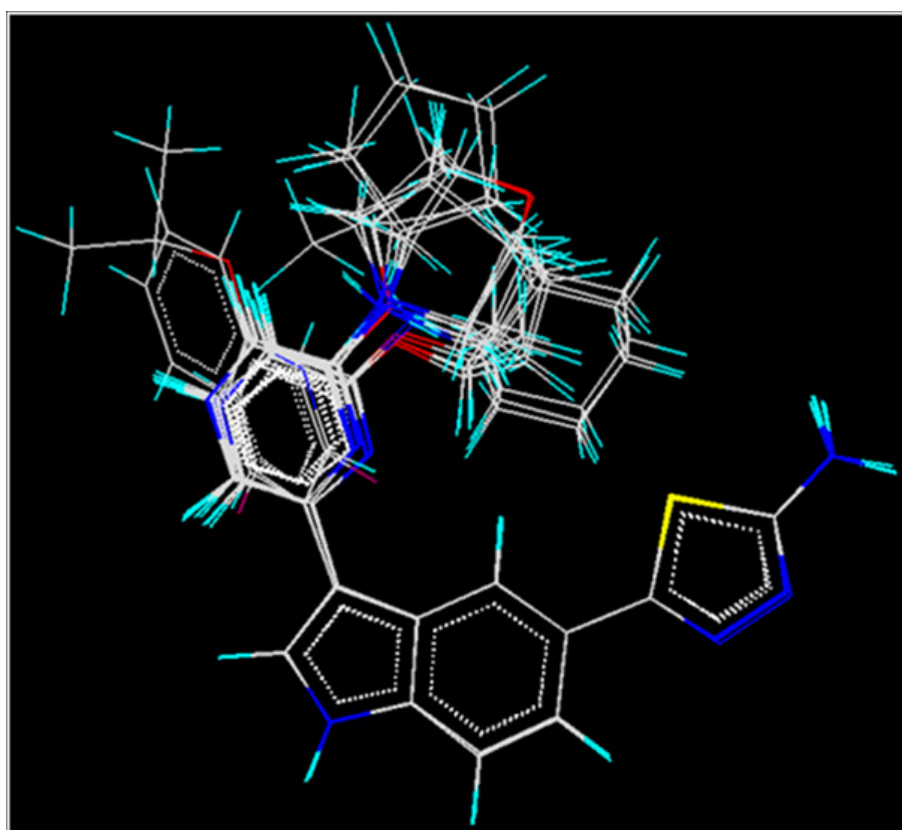

Figure 1: Template based alignment of all the molecules.

1.0576 respectively (Figure 4, Figure 5). The negative coefficient of electrostatic value of first lattice point is indicating that a less electronegative group at this point is favorable for more potent activity whereas positive coefficient of E_630 lattice point is indicating the need of a more electronegative group to be better for biological activity. The positive coefficient of hydrophobic field lattice point suggests the requirement of a hydrophobic group at this point. All the compounds with an alkyl or ring substituent around the hydrophobic field point have good potency, thus indicating that these groups are indeed necessary for better biological activity. E_157 is away from the substitution site which indicates that a more electronegative group at the substitution site would be favorable. On the other hand E_630 is near the main nucleus consisting of substituted thiadiazole moiety indicating the favorable electronegative group for the activity. The various statistical parameters of both the most significant models are given in Table 4. The Y-randomization test for both the models indicated that both the models were able to predict training set compounds with more than $99 \%$ and external compounds with $95 \%$ confidence. The robustness parameters are shown in Table 6. 
Kumar et al.: 3D QSAR Study on thiadiazoles as PIM-1 Inhibitors

Table 5 : Observed, predicted and residual values of the best models

\begin{tabular}{|c|c|c|c|c|c|c|}
\hline \multirow[b]{2}{*}{ S. No. } & \multirow{2}{*}{$\begin{array}{c}\text { Compound } \\
\text { No. }\end{array}$} & \multirow{2}{*}{$\begin{array}{l}\text { Actual } \\
\text { Values }\end{array}$} & \multicolumn{2}{|c|}{ Model 1} & \multicolumn{2}{|c|}{ Model 2} \\
\hline & & & $\begin{array}{l}\text { Predicted } \\
\text { Value }\end{array}$ & $\begin{array}{l}\text { Residual } \\
\text { Values }\end{array}$ & $\begin{array}{l}\text { Predicted } \\
\text { Value }\end{array}$ & $\begin{array}{c}\text { Residual } \\
\text { Values }\end{array}$ \\
\hline 1 & 3 & 6.79 & 6.99 & -0.20 & 6.73 & 0.05 \\
\hline 2 & 13 & 6.75 & $6.78^{*}$ & $-0.02^{\star}$ & 6.64 & 0.11 \\
\hline 3 & 14 & 6.06 & 6.02 & 0.04 & 6.50 & -0.44 \\
\hline 4 & 15 & 7.32 & $6.89^{*}$ & $0.43^{*}$ & 7.53 & -0.21 \\
\hline 5 & 16 & 7.80 & 7.74 & 0.06 & $7.36^{*}$ & $0.44^{*}$ \\
\hline 6 & 17 & 7.62 & 7.81 & -0.19 & 7.98 & -0.36 \\
\hline 7 & 18 & 7.92 & 8.26 & -0.34 & $7.99^{*}$ & $-0.07^{\star}$ \\
\hline 8 & 19 & 6.96 & 7.41 & -0.45 & $7.52^{*}$ & $-0.55^{\star}$ \\
\hline 9 & 20 & 6.85 & 6.79 & 0.06 & $7.13^{*}$ & $-0.29^{*}$ \\
\hline 10 & 21 & 7.96 & 8.20 & -0.24 & 8.24 & -0.29 \\
\hline 11 & 22 & 8.30 & $8.11^{\star}$ & $0.20^{*}$ & $8.26^{*}$ & $0.04^{*}$ \\
\hline 12 & 23 & 8.70 & 8.49 & 0.21 & 8.42 & 0.28 \\
\hline 13 & 24 & 9.00 & 8.74 & 0.26 & 8.80 & 0.20 \\
\hline 14 & 25 & 8.40 & 8.03 & 0.37 & 8.23 & 0.16 \\
\hline 15 & 26 & 7.77 & 7.37 & 0.40 & 7.15 & 0.62 \\
\hline 16 & 27 & 8.16 & 7.69 & 0.46 & 7.53 & 0.62 \\
\hline 17 & 28 & 7.82 & 7.71 & 0.11 & 7.75 & 0.07 \\
\hline 18 & 29 & 7.39 & $7.71^{\star}$ & $-0.32^{\star}$ & 7.74 & -0.35 \\
\hline 19 & 30 & 7.68 & 7.86 & -0.18 & 7.91 & -0.24 \\
\hline 20 & 31 & 8.10 & $8.28^{*}$ & $-0.19^{*}$ & 8.05 & 0.05 \\
\hline 21 & 32 & 7.96 & 8.31 & -0.35 & 8.25 & -0.29 \\
\hline 22 & 33 & 6.58 & $6.71^{*}$ & $-0.13^{*}$ & $6.92^{*}$ & $-0.33^{*}$ \\
\hline
\end{tabular}

* Test set compounds

Table 6 : Robustness statistics for both the most significant models

\begin{tabular}{|c|c|c|c|c|c|c|c|c|c|}
\hline $\begin{array}{c}\text { Model } \\
\text { No. }\end{array}$ & $\begin{array}{c}\text { ZScore } \\
\mathrm{R} \wedge 2\end{array}$ & $\begin{array}{c}\text { ZScore } \\
Q \wedge 2\end{array}$ & $\begin{array}{c}\text { Best Rand } \\
\quad \mathrm{R} \wedge 2\end{array}$ & $\begin{array}{c}\text { Best } \\
\text { Rand } Q \wedge 2\end{array}$ & $\begin{array}{c}\text { Alpha } \\
\text { Rand } R \wedge 2\end{array}$ & $\begin{array}{c}\text { Alpha } \\
\text { Rand } Q^{\wedge} 2\end{array}$ & $\begin{array}{c}\text { Z Score } \\
\text { Pred R^2 }\end{array}$ & $\begin{array}{l}\text { Best Rand } \\
\text { Pred R^2 }\end{array}$ & $\begin{array}{c}\text { alpha Rand } \\
\text { Pred } R^{\wedge} 2\end{array}$ \\
\hline 1 & 4.05 & 3.70 & 0.67 & 0.44 & 0.00 & 0.00 & 1.86 & 0.43 & 0.05 \\
\hline 2 & 4.07 & 2.81 & 0.63 & 0.34 & 0.00 & 0.01 & 2.11 & 0.62 & 0.05 \\
\hline
\end{tabular}
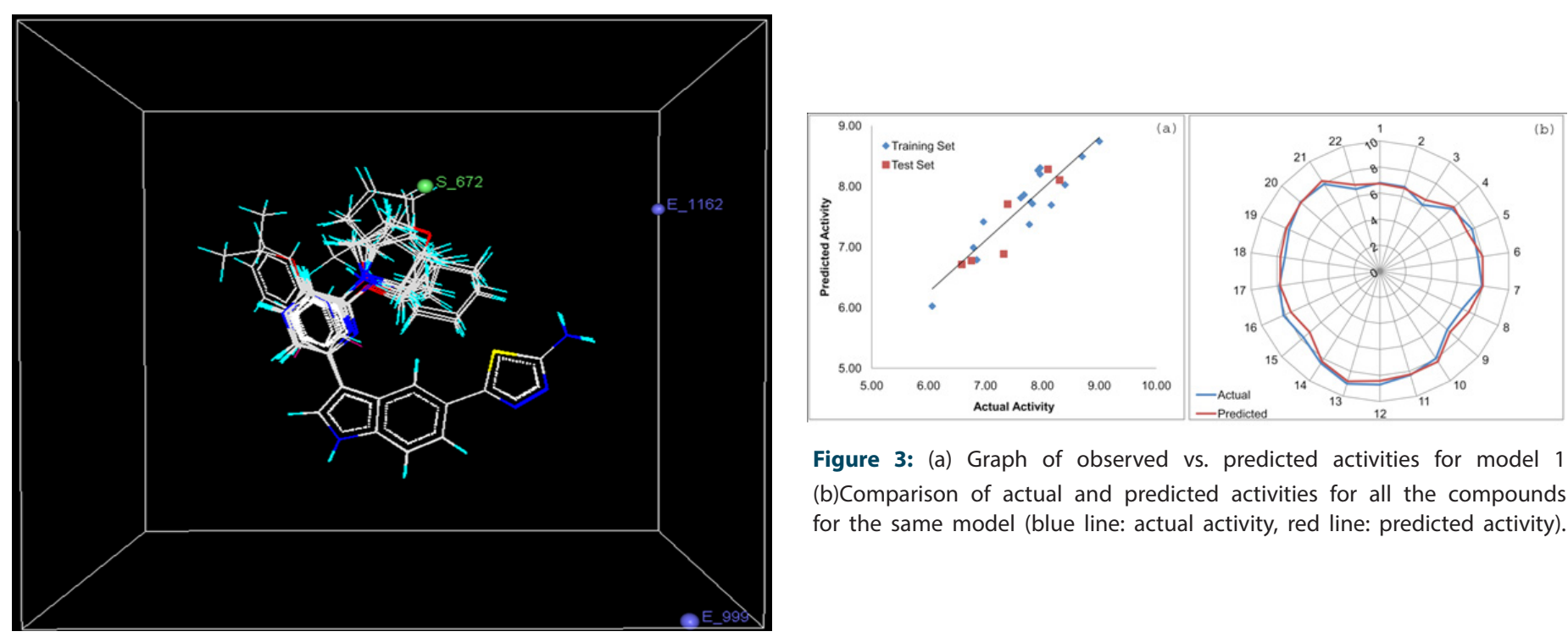

Figure 3: (a) Graph of observed vs. predicted activities for model 1 (b)Comparison of actual and predicted activities for all the compounds for the same model (blue line: actual activity, red line: predicted activity).

Figure 2: Contribution 3D plot for model 1. 


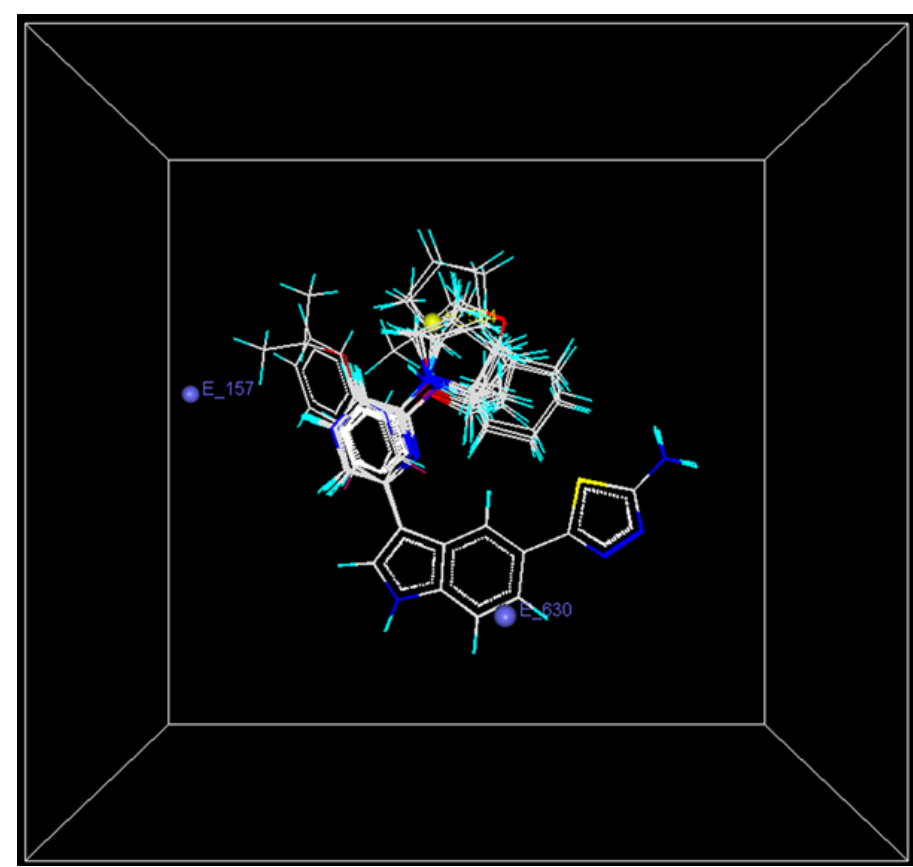

Figure 4: Contribution 3D plot for model 2.

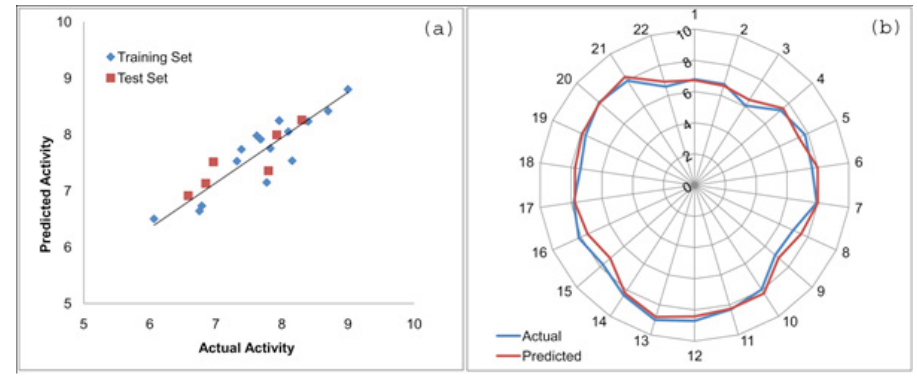

Figure 5: (a) Graph of observed vs. predicted activities for model 2.

(b) Comparison of actual and predicted activities for all the compounds for the same model (blue line: actual activity, red line: predicted activity).

\section{CONCLUSION}

The present study attempts to establish 3D QSAR between a set of 1,3,4-thiadiazol-2-amines and their PIM inhibitory activity. Steric, electrostatic and hydrophobic descriptors were considered for model development through PLSR. The compounds were divided into training and test sets ( $75 \%$ training set and $25 \%$ test set) by random selection method. Three types of Variable selection methods were applied (1) Stepwise Variable selection (SW), (2) Genetic algorithm (GA) and (3) Simulated annealing (SA) with individually ten trials run. Two most significant models generated by GA were selected among the developed models for description on the basis of their internal and External validation parameters and robustness $\left(\mathrm{q}^{2}\right.$ and pred_ $\mathrm{r}^{2}$ respectively). Model 1 and 2 have $q^{2}$ values of 0.7523 and 0.6577 and pred_ $r^{2}$ values of 0.8714 and 0.7675 respectively. The steric field point in model 1 suggests the need of more bulky group at this position and the positive coefficients of electrostatic field points at positions E_999, E_1162 respectively indicate the need of electronegative groups for favorable biological activity and model 2 suggest the requirement of a positive hydrophobic group at H_564 and less electronegative and more electronegative group at E_157 and E_630 respectively for more potent biological activity. Thus more bulky and/or hydrophobic R groups apart from the electrostatic contribution may be favorable for better PIM-1 inhibitory activity of 5- $(1 \mathrm{H}$ - indol-5-yl)-1, 3, 4-thiadiazol-2 amines. For designing of the newer PIM inhibitors with better anticancer activity the structural information from this study may be helpful.

\section{ACKNOWLEDGEMENT}

We are thankful to the Head, SLT Institute of Pharmaceutical Sciences, Guru Ghasidas Vishwavidyalaya (A Central University), Bilaspur (Chhattisgarh) for providing us necessary facilities for the present work.

\section{CONFLICTING INTEREST}

No conflict of interest are declared.

\section{ABBREVIATION USED}

ATP: Adenosine triphosphate; BAD: B-cell lymphoma 2-associated death promoter; MALT: mucosa-associated lymphoid tissue, MYC: myelocytomatosis; PIM: Proviral integration site for moloney murine leukemia virus; PLSR: partial least squares regression; PTK/STAT: Protein tyrosine kinase/signal transducer and activator of transcription; QSAR: Quantitative structure activity relationship.

\section{REFERENCES}

1. Wu B, Wang $H-L$, Cee VJ, Lanman BA, Nixey $T$, Pettus $L$, et al. Discovery of 5-(1 H-indol-5-yl)-1,3,4-thiadiazol-2-amines as potent PIM inhibitors. Bioorg Med Chem Lett. 2015;25(4):775-80.

2. Dakin LA, Block MH, Chen H, Code E, Dowling JE, Feng $X$, et al. Discovery of novel benzylidene-1,3-thiazolidine-2,4-diones as potent and selective inhibitors of the PIM-1, PIM-2, and PIM-3 protein kinases. Bioorg Med Chem Lett. 2012;22(14):4599-604.

3. Foulks JM, Carpenter KJ, Luo B, XuY, Senina A, Nix R, et al. A Small-Molecule inhibitor of PIM Kinases as a potential treatment for Urothelial Carcinomas. Neoplasia. 2014;16(5):403-12.

4. Pasqualucci L, Neumeister P, Goossens T, Nanjangud G, Chaganti R. S. K, Küppers R, et al. Hypermutation of multiple proto-oncogenes in B-cell diffuse large-cell lymphomas. Nature. 2001;412(6844):341-5.

5. More KN, Jang HW, Hong VS, Lee J. PIM kinase inhibitory and antiproliferative activity of a novel series of meridianin C derivatives. Bioorg Med Chem Lett. 2014;24(11): 2424-8.

6. Alegaon SG, Alagawadi KR, Sonkusare PV, Chaudhary SM, Dadwe DH, Shah AS Novel imidazo[2,1-b][1,3,4]thiadiazole carrying rhodanine-3-acetic acid as potential antitubercular agents. Bioorg Med Chem Lett. 2012;22(5):1917-21.

7. Gadad AK, Noolvi MN, Karpoormath RV. Synthesis and anti-tubercular activity of a series of 2-sulfonamido/trifluoromethyl-6-substituted imidazo-[2,1-b]-1,3,4thiadiazole derivatives. Bioorg Med Chem. 2004;12(21):5651-9.

8. Kolavi G, Hegde V, Khazia IA, Gadad P. Synthesis and evaluation of antitubercular activity of imidazo[2,1-b][1,3,4]thiadiazole derivatives. Bioorg Med Chem. 2006;14(9):3069-80

9. Romagnoli R, Baraldi PG, Prencipe F, Balzarini J, Liekens S, Estevez F. Design, synthesis and antiproliferative activity of novel heterobivalent hybrids based on imidazo[2,1-b][1,3,4]thiadiazole and imidazo[2,1-b] [1,3]thiazole scaffolds. Eur J Med Chem. 2015;101:205-17.

10. Kumar S, Gopalakrishnan V, Hegde M, Rana V, Dhepe SS, Ramareddy SA, et al. Synthesis and antiproliferative activity of imidazo[2,1-b][1,3,4]thiadiazole derivatives. Bioorg Med Chem Lett. 2014;24(19):4682-8.

11. Gadad AK, Mahajanshetti CS, Nimbalkar S, Raichurkar A. Synthesis and antibacterial activity of some 5-guanylhydrazone/thiocyanato-6-arylimidazo [2,1-b]1,3,4-thiadiazole-2-sulfonamide derivatives. Eur J Med Chem. 2000;35(9): 853-7.

12. Puttaraju KB, Shivashankar K, Chandra, Mahendra M, Rasal VP, Vivek PNV et al. Microwave assisted synthesis of dihydrobenzo [4,5] imidazo [1,2-a] pyrimidin-4-ones; synthesis, in vitro antimicrobial and anticancer activities of novel coumarin substituted dihydrobenzo [4,5] imidazo [1,2-a] pyrimidin-4-ones. Eur J Med Chem. 2013;69:316-22.

13. Noolvi MN, Patel HM, Kamboj S, Kaur A, Mann V. 2,6-Disubstituted imidazo [2,1-b] [1,3,4] thiadiazoles: Search for anticancer agents. Eur J Med Chem. 2012;56:56-9.

14. Terzioglu N, Gursoy A. Synthesis and anticancer evaluation of some new hydrazone derivatives of 2,6-dimethylimidazo $[2,1-b]-[1,3,4]$ thiadiazole-5-carbohydrazide. Eur J Med Chem. 2003;38(7):781-6.

15. Karki SS, Panjamurthy K, Kumar S, Nambiar M, Ramareddy SA, Chiruvella KK et al. Synthesis and biological evaluation of novel 2-aralkyl-5-substituted-6-(40fluorophenyl)-imidazo [2,1-b] [1,3,4] thiadiazole derivatives as potent anticancer agents. Eur J Med Chem. 2011;46(6):2109-16. 
Kumar et al.: 3D QSAR Study on thiadiazoles as PIM-1 Inhibitors

16. Alwan WS, Karpoormath R, Palkar MB, Patel HM, Rane RA, Shaikh MS et al. Novel imidazo [2,1-b]-1,3,4-thiadiazoles as promising antifungal agents against clinical isolate of Cryptococcus neoformans. Eur J Med Chem. 2015; 95: 514-25.

17. Lamani RS, Shetty NS, Kamble RR, Khazi IAM. Synthesis and antimicrobial studies of novel methylene bridged benzisoxazolyl imidazo [2,1-b] [1,3,4] thiadiazole derivatives. Eur J Med Chem. 2009;44(7):2828-33.

18. Patel HM, Noolvi MN, Goyal A, Thippeswamy BS. 2,5,6-Trisubstituted imidazo [2,1-b] $[1,3,4]$ thiadiazoles: Search for antihyperlipidemic agents. Eur J Med Chem. 2013;65:119-33.

19. Jadhav VB, Kulkarni MV, Rasal VP, Biradar SS, Vinay MD. Synthesis and antiinflammatory evaluation of methylene bridged benzofuranyl imidazo [2,1-b] [1,3,4] thiadiazoles. Eur J Med Chem. 2008;43(8):1721-9.

20. Nishiguchi GA, Atallah G, Bellamacina C, Burger MT, Ding Y, Feucht PH et al. Discovery of novel 3,5-disubstituted indole derivatives as potent inhibitors of PIM-1, PIM-2, and PIM-3 protein kinases. Bioorg Med Chem Lett. 2011.
21(21):6366-9.

21. Valentina $P$, llango $K$, Yamuna $K$, Purushothaman $D$, Samyuktha RA. QSAR Analysis on $\beta$-carboline as Antitumor Agent. J Young Pharm. 2009;1(1):77-81.

22. Ganguly S, Mishra R. Comparative Molecular Similarity Indices Analysis of 1-(Naphthylalky1)-1 H-imidazole Analogs with Antiepileptic Activity. J Young Pharm. 2010;2(4):388-93.

23. Islam Md R, Zaman A, Jahan I, Chakravorty R, Chakraborty S. In silico QSAR analysis of quercetin reveals its potential as therapeutic drug for Alzheimer's disease. J Young Pharm. 2013;5(4):173-9.

24. Satpathy R, Ghosh S. In-silico Comparative Study and Quantitative Structureactivity Relationship Analysis of Some Structural and Physiochemical Descriptors of Elvitegravir Analogs. J Young Pharm. 2011;3(3):246-9.

25. VLife MDS: Molecular Design Suite, VLife Sciences Technologies Pvt. Ltd., Pune, India, 2010 (www.vlifesciences.com).

Article History: Submission Date: 05-10-16; Received Date: 27-10-16; Acceptance Date: 28-12-16.

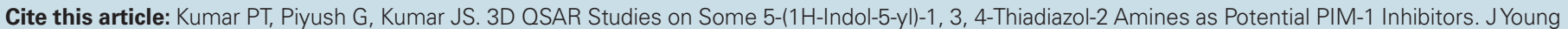
Pharm. 2017;9(2):162-7. 